\title{
PRÁCTICAS ACADÉMICAS DE PRODUCCIÓN Y DISTRIBUCIÓN DEL CONOCIMIENTO \\ EN LA ERA DIGITAL. (Y UNA REFLEXIÓN SOBRE CÓMO TRANSFORMARLAS DESDE AMÉRICA LATINA)
}

\author{
ACADEMIC PRACTICES OF PRODUCTION AND DISTRIBUTION OF \\ KNOWLEDGE IN THE DIGITAL ERA. (AND A DISCUSSION OF \\ HOW THEY CAN BE TRANSFORMED FROM LATIN AMERICA)
}

\section{CAROLINA GAINZA*}

\section{RESUMEN}

El artículo aborda algunas problemáticas relacionadas con la transformación de la producción y circulación de conocimientos en la era digital, y cómo éstas han afectado la práctica académica, poniendo especial énfasis en la situación latinoamericana $y$, a modo de ejemplo, el caso chileno. El artículo se pregunta por el papel de las humanidades en este contexto y discute algunos aspectos propios de las formas de circulación del conocimiento en América Latina, y su situación en el contexto mundial, así como algunas posibilidades abiertas por el contexto digital.

Palabras clave: Revistas académicas, investigación, humanidades, acceso abierto, indexación.

\section{ABSTRACT}

In this article I will discuss some issues related to the transformation of the production and circulation of knowledge in the digital era, and how these processes affect the academic practice, focusing on Latin America and the case of Chile. The article's goal is to discuss the role of humanities in this context and analyze some specific aspects that concern the circulation of knowledge in Latin America as well as the possibilities opened by the digital context.

Keywords: Academic journals, humanities, research, open access, indexing.

Recibido: 11.04.16. Aceptado: 30.08.16.

${ }^{*}$ PhD. Hispanic Languages and Literatures, Escuela de Literatura Creativa, Facultad de Comunicación y Letras, Universidad Diego Portales. Santiago, Chile. Correo electrónico: carolina. gainza@udp.cl 
A POSTURA CRítica de quienes pertenecemos a las humanidades ha permitido que nuestra producción intelectual esté relacionada, en alguna o gran medida, con el proceso de develar diversas formas de opresión, dominación y exclusión. De esta forma, hemos visto en el último tiempo a intelectuales y académicos, en diversas partes del mundo, apoyando y mostrando su simpatía por las protestas estudiantiles, Occupy Wall Street, los indignados, entre otras movilizaciones de protesta y movimientos sociales. Todos estos movimientos aluden a lo que, a mi juicio, constituye el gran conflicto de nuestra época: la usurpación de lo común. Con esto nos referimos a lo común en la educación, lo común en la producción de conocimientos, lo común en la producción biotecnológica, todo lo cual apunta a la privatización de lo que se considera común a la humanidad y que así debería quedar. Sin embargo, los principios que guían estos movimientos ¿̇han modificado en algo la práctica académica de producción y transmisión de conocimientos?

El artículo va a discutir algunas de las variables relacionadas con la problemática que plantea esta pregunta. En primer lugar, se presentará el contexto en que se levanta el conflicto en torno a la producción de conocimiento, en estrecha relación con el desarrollo de las tecnologías digitales. En segundo lugar se discutirán los desafíos que esto plantea a las formas de producción y circulación del conocimiento dentro de la práctica académica, especialmente en relación con las trabas existentes respecto a la circulación de conocimientos en la situación Latinoamericana. Finalmente se busca instalar una discusión respecto a las posibles salidas a estos problemas.

\section{LA PROPIEDAD INTELECTUAL Y LA APROPIACIÓN DE LO COMÚN: CONFLICTOS EN LA ERA DIGITAL}

La circulación del conocimiento y la información en Internet es quizás uno de los fenómenos más importantes de nuestra era, y posee una viralidad que, por las características materiales de lo digital, se hace casi imposible de controlar. Podemos encontrar en Internet millones de películas, libros, música, artículos académicos, software e investigaciones que escapan de las manos de las industrias que hasta hace unos años eran las encargadas de controlar su distribución.

La digitalización de la producción cultural ha permitido que ese control pase en gran medida a los usuarios, lo cual afecta directamente el ejercicio de la propiedad intelectual. En este sentido, la propiedad intelectual se ha 
convertido en el terreno de uno de los principales conflictos de nuestra época. Burlar estos derechos en Internet significa un ataque principalmente a la industria que hasta hace poco controlaba la circulación de mercancías. Por primera vez en siglos observamos una forma de circulación que no está orientada por la ganancia, sino más bien a permitir el acceso a la información, el conocimiento y la entretención.

Las condiciones materiales de existencia en las cuales se desarrollan Internet, telefonía celular, software y diferentes dispositivos electrónicos -donde las prácticas de reproducción, repetición, copia y traspaso de información se han convertido en formas incontrolables de compartir conocimientos- son el resultado de los usos que diversos actores sociales hacen de la tecnología. El intercambio de conocimientos e información que se observa en las redes ha dado forma a una práctica del compartir generali$\mathrm{zada}^{1}$, que la mayoría de las veces infringe derechos de autor y propiedad intelectual. Así, son los derechos de propiedad intelectual, aquellos que ponen énfasis en un propietario individual, que surgen con la época moderna y que son parte fundamental del capitalismo moderno, los que están siendo cuestionados y transgredidos por las prácticas de quienes adhieren a esta filosofía, o, como ellos la llaman, ética del compartir. La piratería, en este sentido, se ha convertido en una práctica cultural de crítica y resistencia. Frente a este panorama podríamos afirmar que, en la época de reproductibilidad digital, preguntarse por el autor o la producción original carece de sentido.

En efecto, Mercedes Bunz en su "utopía de la copia" señala que "el ajuste a un origen, el ajuste a un centro, es reemplazado por una progresión sin centro. La lógica de la representación es disuelta por la lógica de la repetición" (Bunz, 2007, p. 18). De esta forma, la estética de la reproductibilidad técnica propuesta y analizada por Walter Benjamin (2007) es reemplazada en la era digital por una estética de la repetición. Para el autor, aunque con cada reproducción el original perdía su aura, siempre existía como referente, como identidad originaria. En cambio, la repetición obedece a una copia sin centro, la repetición es pura duplicación, copia de la copia. Si la copia

\footnotetext{
${ }^{1}$ Quienes adhieren a esta ética de compartir se agrupan bajo el movimiento cultura libre. Sin embargo, es necesario dejar claro que libre no significa gratis. Las personas pueden cobrar por sus producciones, siempre y cuando esto no signifique lucrar con los bienes comunes, entendiendo el lucro como práctica de acumulación de capital que priva a otros del acceso a estos bienes. Este "no lucrar" significa además que, cuando una persona vende su producto, es necesario que ceda sus derechos sobre lo producido, ya que para el movimiento por la cultura libre, toda producción individual es informada por una producción colectiva y común y, por lo tanto, patentar o licenciar una obra de arte, novela, software, un código genético, un artículo de investigación u otra forma de conocimiento, es arrancarlo de la comunidad.
} 
está en todos lados, ¿cuál es el original? El original se borra cada vez que una copia se duplica. Cada copia, por decirlo de otra manera, es un original desde donde se pueden realizar más copias. Así la lógica de la originalidad se diluye, "la duplicación sustituye la oposición entre original y copia" (Bunz, 2007, p. 32). Esta estética de la repetición la podemos encontrar en múltiples trabajos de literatura digital, así como también en las técnicas del remix y el sampling que ocurren en la música y en el cine. También, la lógica de la repetición se manifiesta como forma de circulación, ya que "el acto de copiar se vuelve una forma de transporte" (Bunz, 2007, p. 19). En este sentido, la repetición, tanto como elemento de la creación, producción y circulación de información y conocimientos, constituye una característica fundamental y definitoria de una estética que deriva en prácticas políticas.

Está estética y práctica de la repetición elimina, o al menos corroe, la acumulación del capital. Utilizando Internet, todos hemos experimentado la facilidad con la que podemos acceder a múltiples textos, películas, música, software, información y conocimientos variados, que ya no están en manos de la industria o de un autor, sino que se reproducen viralmente, a pesar de los controles que se quieren establecer sobre ellos. En este sentido, la propiedad capitalista es subvertida en Internet, y es ahí donde Bunz identifica su potencial utópico: "la duplicación altera la acumulación" (Bunz, 2007, p. 19). La forma distribuida y dispersa de las redes que se generan en Internet -existen múltiples sitios donde compartir archivos de todo tipo- hace casi imposible su desconexión. Ahí donde se baja o prohíbe el funcionamiento de una web para compartir archivos, surgen otros nuevos en la red.

La búsqueda de eliminación de las barreras de acceso al conocimiento e información se vincula fuertemente con la práctica de repetición viral propiciada por la materialidad digital y sus consecuencias políticas. Si bien la lógica de expropiación del trabajo colectivo, o de los bienes comunes, ha sido siempre parte del sistema de acumulación capitalista, en la actualidad el conflicto por la apropiación de lo común se hace patente en los intentos de control y medidas desesperadas por parte de industrias culturales, de software, farmacéuticas, genéticas, y también, el mundo académico, sector en el que se ha desarrollado una industria del paper, principalmente en la forma de revistas académicas en que se debe pagar por el acceso a los artículos.

Un buen ejemplo para observar cómo se desenvuelve este conflicto en el ámbito académico es el emblemático caso de Aaron Swartz. Hacker y activista por el acceso libre al conocimiento, Swartz, que al momento de 
su muerte tenía 26 años, se hizo conocido por una acusación judicial por intentar liberar artículos académicos contenidos en $\mathrm{JSTOR}^{2}$ a través de la red del MIT (Massachusetts Institute of Technology) con el objetivo de ponerlos a disposición de los lectores, utilizando redes $\mathrm{P}_{2} \mathrm{P}^{3}$. El desenlace es bien conocido: El MIT y JSTOR interpusieron cargos en su contra, no sólo por bajar 4,8 millones de archivos, entre artículos, reseñas y otros documentos, sino que por compartirlos en otros sitios de descargas. Realmente el problema no era que Swartz hubiera bajado los documentos, ya que era estudiante de Harvard y por lo tanto tenía acceso legal a JSTOR, sino que él hubiera compartido esos archivos. La justicia estadounidense lo persiguió fuertemente, para transformar su caso en un precedente ejemplificador en el marco de los delitos informáticos. Sin embargo, no había delito. La acción de Swartz fue un caso de desobediencia civil, al poner en tela de juicio la ley de copyright y la función de repositorios de revistas académicas en el negocio de la información y el conocimiento. No era un delito, ya que bajó los artículos en su calidad de estudiante de Harvard y no llegó a hacer circular los papers que bajó de JSTOR.

Sin embargo, Swartz arriesgaba el pago de varios millones de dólares y hasta cincuenta años de cárcel, después de que la justicia estadounidense aumentara los cargos en su contra de cuatro a trece, buscando argumentos para condenarlo de cualquier manera. El juicio no llegó a concretarse en una condena: Swartz se suicidó y fue encontrado muerto en su departamento el 11 de enero de 2013. Si bien sus cercanos señalan que su suicidio fue producto de una depresión que le afectaba hacía varios años, en el imaginario colectivo prima que la persecución en su contra fue lo que gatilló su decisión. Así, en vez de convertirse en un precedente para el castigo de delitos informáticos en los Estados Unidos, su caso de "desobediencia" se convirtió en emblema de la lucha por el acceso al conocimiento. Rápidamente se desarrollaron protestas en la red, como el hackeo de la página del

\footnotetext{
2 JSTOR es una ONG fundada en 1995 en los Estados Unidos. Consiste en un sistema de archivos en línea que reúne artículos académicos, vinculados a más de 1.500 revistas académicas de distintas disciplinas, a los cuales pueden acceder bibliotecas y universidades de todo el mundo que posean un acuerdo, monetario por supuesto, con JSTOR. Además permite a individuos y otras instituciones particulares suscribirse mediante pago, para poder tener acceso a revistas $\mathrm{y}$ artículos.

${ }^{3}$ P2P es la sigla de "peer to peer", la cual consiste en una serie de computadores interconectados que funcionan como nodos que permiten intercambiar y compartir información. Son redes anónimas que han permitido acceder y compartir libros, películas, música, software, conocimientos, e información en general, y que, por razones obvias, han sido cuestionadas por quienes defienden los derechos de propiedad intelectual o copyright.
}

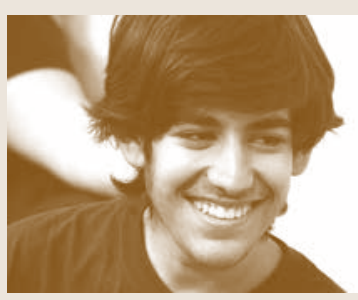

A. Swartz 

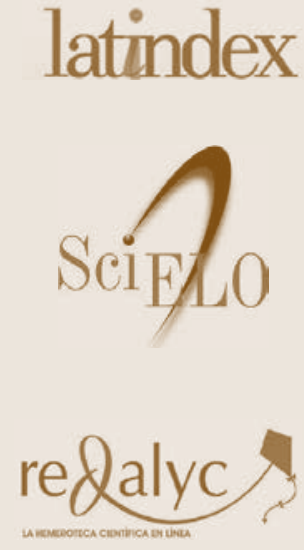

MIT y del Departamento de Justicia estadounidense por parte del grupo Anonymous. Además se realizaron homenajes, de los cuales quizás el más significativo -y en directa relación con el llamado que busca hacer el presente artículo- fue el pdf tribute, en el cual se llamó a los académicos de todas las áreas del conocimiento a poner sus artículos -publicados o no publicados, con copyright o sin él- en la red, como una forma de hacer realidad lo que Swartz buscaba hacer con los millones de artículos que bajó de JSTOR: liberar el conocimiento ${ }^{4}$.

La acción subversiva de Swartz no se dirigió sólo hacia la industria que se ha generado en torno a las revistas académicas, demostrando el potencial que tiene lo digital para cuestionar este sistema (así como pasa en la música, el cine, y otras industrias de la cultura), sino que, además, su acción evidencia la relación estrecha que tiene el sistema de derechos de autor con el desarrollo de la industria editorial y/o quienes gestionan esos derechos.

\section{EL MODELO DE ACCESO ABIERTO EN AMÉRICA LATINA: ACIERTOS Y CONFLICTOS}

Frente a las prácticas privatizadoras del conocimiento, el acceso abierto se ha mostrado como una alternativa que comenzó a tomar fuerza hace algunos años frente a las revistas pagadas, donde la presencia de estas últimas ha aumentado exponencialmente en los países del norte hasta causar la indignación de los mismos investigadores que publican en ellas. Sin embargo, como señala el informe de Ana María Cetto y José Octavio Alonso-Gamboa titulado "Latindex y el acceso abierto" (2014), la práctica de "Open Access" ha sido una constante en las revistas académicas latinoamericanas. Efectivamente, si miramos las revistas latinoamericanas del área de humanidades que publican sus números online, observaremos que en su mayoría es posible acceder a todos los artículos de forma libre y gratuita, tanto en las páginas web de las revistas como a través de repositorios como RedALyC, Latindex o Scielo.

Sin embargo, no ocurre lo mismo para acceder a las revistas publicadas en el hemisferio norte, donde se aprecia un importante negocio ${ }^{5}$ respecto a la gestión del conocimiento, el cual deja cautivos tanto a lectores, al tener que pagar por acceder a los artículos, como a los autores, que ceden sus de-

\footnotetext{
${ }^{4}$ Esto se realizó por medio de Twitter, bajo el hashtag \#pdftribute, y además se creó un sitio web que recoge todos los tweets asociados a este hashtag (www.pdftribute.net).

${ }^{5}$ En el caso de las revistas de ciencia, la editorial Elsevier (que tiene entre sus productos el portal science direct y las prestigiosas revistas Genomics y Cell, entre otras) cobra altas cifras por
} 
rechos a la revista para poder difundir sus artículos. Esta desigualdad en el acceso al conocimiento se ve fomentada desde nuestros propios países por la forma en que se gestiona la difusión de los resultados de investigación, lo cual depende de los sistemas de evaluación de la producción de los investigadores en cada país.

¿Cuál es el destino de los resultados de investigaciones financiadas con fondos públicos? En Chile, la institución que evalúa los resultados de los proyectos de investigación financiados con fondos públicos (CONICYT, a través de su programa FONDECYT) evalúa positivamente la difusión de los resultados de estas investigaciones en revistas indexadas, ojalá internacionales, dado que son las que tienen mayores índices de impacto. Como las revistas con mejores índices pertenecen a instituciones norteamericanas o europeas que funcionan bajo un régimen que restringe el acceso a sus artículos en función de un pago, estamos frente a una situación en que la investigación financiada en nuestros países con fondos públicos termina en revistas por las cuales debemos pagar para poder acceder. La situación es, a todas luces, absurda y fomenta el negocio de las editoriales académicas extranjeras que no entregan ningún beneficio ni a nuestros países ni a los investigadores, salvo el estatus, individual del investigador y de la institución, de haber publicado en una de esas revistas. Por otra parte, se perjudica al público lector, ya que la población de nuestros países, tanto estudiantes como investigadores, no pueden acceder a artículos de investigación, a no ser que la institución donde estudian o trabajan haya pagado por el acceso a este tipo de revistas. Estamos frente a un círculo vicioso que privatiza el conocimiento producido en nuestros países y a una forma de dependencia

el acceso a los artículos publicados en sus revistas, donde los autores no se benefician de estas ganancias e incluso deben pagar para poder hacer circular sus propios artículos. En las humanidades uno de los sistemas más prestigiosos es el Arts and Humanities Citation Index (A\&HCI), perteneciente a la Web of Science (WoS, y anteriormente conocida como ISI). Este sistema de información científica y bases de datos es manejado por el conglomerado editorial Taylor and Francis, que certifica la calidad de las revistas y al mismo tiempo genera un negocio vinculado principalmente a su distribución, al cual pertenecen revistas como Verso, New Left Review e Historical Materialism, muchas de ellas consideradas como las de mayor prestigio dentro del sistema de indexación vigente. Es importante señalar que recientemente Thomson Reuters anunció que llegó a acuerdos para vender su "negocio de ciencia y propiedad intelectual", WoS, a Onex Corporation and Baring Private Equity Asia, en 3,5 billones de dólares. En cuanto a Elsevier, en el año 2012 científicos de diversas áreas iniciaron un boicot contra la compañía debido al precio exorbitante de sus artículos, sus prácticas abusivas respecto a los autores y su apoyo a proyectos como SOPA (Stop Online Piracy act), RWA (Research Works Act) y PIPA (Protect IP act). Las acciones de estos científicos consistieron en negarse a publicar, evaluar o editar artículos para las revistas de la editorial y recolectar firmas para denunciar sus malas prácticas vinculadas al acceso al conocimiento. 
que comercializa nuestros recursos intelectuales e instala barreras de acceso a los conocimientos generados por nosotros mismos.

Otro aspecto importante e íntimamente vinculado a la discusión sobre el acceso libre, es el copyright. Aunque es muy positivo que exista acceso libre en la mayoría de las revistas latinoamericanas en humanidades, el problema es que esta condición no significa que este tipo de publicaciones estén libres del sistema de copyright. Este sistema de propiedad intelectual limita de varias formas la circulación del conocimiento, porque no permite la distribución ni la reproducción.

En el estudio de Alberto Cerda y Juan Carlos Lara (2011) sobre las políticas editoriales de las revistas académicas latinoamericanas publicadas en línea, el cual consideró un 17,4\% (292 revistas) de las publicaciones académicas disponibles en línea indexadas en Latindex, Scielo, y RedALyC 6 , se señala que "por omisión o por expresa declaración, un 75\% de las publicaciones latinoamericanas en línea analizadas adoptan el modelo legal de licenciamiento de sus contenidos, el que, en síntesis, requiere autorización del titular de los derechos a efectos de hacer uso de la obra" (Cerda y Lara, 2011, p. 16). Esa adopción ocurre mayoritariamente por omisión, ya que al no explicitarse el tipo de licenciamiento, se aplica automáticamente el modelo legal imperante. Sólo un $6,2 \%$ utiliza explícitamente licencias creative commons ${ }^{7}$.

El panorama a nivel mundial es mucho peor, ya que toma los casos de los países del norte donde el acceso al conocimiento es mucho más restrictivo. Como señala un informe de Latindex, "en septiembre de 2014, Ulrichsweb reporta que sólo el 8\% (15.544 de 187.616) de las revistas académicas indexadas en su sistema son de tipo acceso abierto" (Cetto y Alonso-Gamboa, 2014, p. 8). Lo anterior representa un obstáculo, dado que el modelo legal de licenciamiento se rige por las leyes del copyright y por lo tanto limita la

\footnotetext{
${ }^{6}$ De las 292 publicaciones académicas incluidas en el estudio, un $23,6 \%$ corresponden a medicina y ciencias de la salud, seguidas por un $22,6 \%$ de publicaciones correspondientes a las ciencias sociales, filosofía y humanidades. Más atrás les siguen disciplinas biología y ciencias (15,8\%), agronomía y ciencias forestales $(6,8 \%)$, economía y administración $(5,1 \%)$, entre otras.

${ }^{7}$ Creative commons es un sistema de licencias que establece una forma de propiedad, pero, a diferencia del copyright, se respeta "lo común" de la obra al permitir su circulación. En estas licencias, el autor decide si quiere liberar su obra totalmente, es decir, que pueda ser modificada, utilizada y distribuida libremente, o poner ciertas restricciones, especialmente respecto a la modificación de la obra. El autor es entendido como actor, un actor clave por cierto, en el proceso de creación, pero esto no significa que pueda ejercer una autoridad sobre la circulación de una obra que se ha construido en base a conocimientos elaborados a partir de diversas tradiciones culturales que informan la producción de conocimientos. En este sentido, la forma de entender la producción de conocimientos es diferente, donde el autor es solo un eslabón de la cadena, y no el punto de partida de un tipo de conocimiento.
} 
circulación de conocimientos; pero a la vez representa una oportunidad, dado que es posible transformar esas omisiones en el tipo de licencias al sistema de licencias "libres", como creative commons (Cerda y Jara, 2011).

A pesar de que el copyright surgió como un sistema que buscaba proteger a los autores en los ámbitos económicos y morales, hoy en día no son siquiera los autores quienes reclaman ese derecho, sino que, como en el caso extremo de conglomerados editoriales como Elsevier o Taylor and Francis, son más bien las industrias quienes los ejercen y es su principal fuente de ganancias. En el ámbito académico esto tiene como resultado el establecimiento de un sistema de circulación de saberes que finalmente no sale de la academia, accesible sólo para quienes estamos en la universidad, ya que la universidad paga nuestro acceso a revistas o tenemos que pagar individualmente el acceso a papers (invirtiendo en esto parte del dinero obtenido para investigación $)^{8}$.

De esta forma, los intelectuales de las disciplinas humanistas y sociales se ven sujetos a un sistema de publicación que, en diversas escalas, limita el acceso al conocimiento, ya sea por lo cobros o por adherir al sistema de copyright ${ }^{9}$. Lo anterior es promovido por una institucionalidad que fuerza a los investigadores a entrar en una máquina de producción de artículos académicos, si es que éstos buscan obtener acceso a fondos de investigación o ser promovidos en la escala académica. Una jaula de hierro nos mantiene encerrados, obligándonos a reproducir y reforzar sus barrotes. ¿ No deberíamos recuperar la capacidad crítica de nuestras disciplinas y pensar un modelo alternativo, que en efecto existe en repositorios como RedALyC, Latindex y Scielo, que permita modificar las prácticas de publicación y difusión del conocimiento, uno que transforme las relaciones sociales en las que nos encontramos inmersos actualmente en la práctica académica en América Latina? ¿Qué oportunidades presenta lo digital para mejorar la circulación y acceso al conocimiento?

\footnotetext{
${ }^{8}$ En efecto, dadas las dificultades existentes, sobre todo para los estudiantes, para acceder a papers, se han creado grupos en Facebook, como el conocido bajo el nombre "bájame este paper". Aquí los estudiantes se ayudan mutuamente para intercambiar artículos académicos a los que tienen acceso en sus universidades. La mayoría de los estudiantes que proveen acceso a papers académicos están estudiando en universidades de los Estados Unidos y Europa.

${ }^{9}$ En casi toda Latinoamérica, el paper académico es el que posee una mayor asignación de puntaje en los concursos a fondos de investigación o en los concursos académicos, respecto al libro o ensayos críticos. En el caso chileno, las revistas que dan más puntaje en los concursos FONDECYT (Fondo Nacional de Investigación Científica y Tecnológica) no son aquellas con acceso abierto, sino que generalmente son revistas que poseen algún tipo de copyright y que se encuentra en el sistema WoS o Scopus.
} 


\section{MÁQUINAS DE PRODUCCIÓN DE PAPERS: AUTORÍA Y LEGITIMACIÓN ACADÉMICA}

Las humanidades son las áreas que más se han visto afectadas con el modelo universitario actual, el cual se ve influenciado crecientemente por la racionalidad económica y política del neoliberalismo. Acorde con este diagnóstico, las formas en que transmitimos el conocimiento desde la academia no son ajenas a la situación en que se encuentran nuestras disciplinas.

Existe toda una institucionalidad que nos impone una forma de construir y difundir saberes. José Santos (2012) señala que las instituciones han llevado a cabo una sistemática campaña que ha posicionado al paper como la forma deseable y aceptable de escritura académica. Además de eso, la producción de artículos académicos se ha transformado en un indicador eficiente de la productividad intelectual de las instituciones y los profesionales. Mientras más papers tenga publicados un académico/académica o institución universitaria -de preferencia indexadas en WoS y/o Scopusmayor prestigio se obtiene y, en el caso de las universidades, esto aumenta su posición en los rankings. En el caso de los/las académicos/as, mientras más papers publiquen, mayores son las posibilidades de obtener becas, financiamiento para investigaciones y ascenso en la escala académica. Ese es nuestro capital, un capital académico, fomentado y reforzado por toda la institucionalidad que anima este tipo de producción y circulación de conocimientos. Así, gran parte de la práctica académica se encuentra asociada, y amarrada a una institucionalidad que restringe la amplia difusión de los saberes. ¿Por qué se acusó a Aaron Swartz? justamente por desobedecer y producir un desvío en el circuito cerrado de producción y circulación de conocimientos.

La drástica transformación en la circulación del conocimiento introducida por los avances tecnológicos y la masificación de las redes digitales no ha sido aprovechada por la institución universitaria para transformarse a sí misma. En un artículo titulado "Pirate Radical Philosophy", escrito por Gary Hall (2012) y publicado en la web del journal Radical Philosophy, el autor se refiere precisamente a la posibilidad de un cambio en las prácticas y las relaciones sociales presentes en la labor académica. Su argumento consiste en que los académicos se han enfocado mayoritariamente en solo decir "no" a la idea de universidad que opera como un negocio, y demandan un retorno al tipo de universidad financiada públicamente, la cual tiene como misión educar a la gente y no sólo producir profesionales funcionales al sistema. En nuestro contexto nacional, extrapolable a América Latina y sus 
diversos movimientos, la labor de los intelectuales en un caso particular, el movimiento estudiantil, se ha limitado a actuar para los estudiantes, protestando con ellos, o hablar sobre ellos, aceptando invitaciones para hablar y escribir acerca de sus demandas. Pero, ¿por qué no actuar en sus términos?, es decir, ¿por qué no pensar en la forma de generar acciones que nos muevan fuera del modelo de producción y difusión del conocimiento imperante en la academia?

Foucault señala en ¿Qué es un autor? (2010) que la noción de autor corresponde a un momento de individualización en la historia de las ideas, conocimientos, literatura, ciencias, entre otros, que se enlaza con el proceso de instauración de derechos de propiedad dentro del proyecto moderno de exaltación del individuo. Para Foucault, el autor no es necesariamente el propietario de los textos que escribe, sino que la obra cobra vida independiente más allá de las reglas que este inicialmente le imponga. El autor liberal-moderno realiza un ejercicio de poder cuando aplica un derecho de propiedad sobre su obra, excluyendo a otros del acceso libre a ésta y, con esto, de la posibilidad de crear a partir de su obra. De esta forma, el conocimiento queda encerrado en un círculo de autores, es arrebatado de la comunidad creativa y arrancado del espacio de lo común.

La producción académica no es ajena a esta lógica del autor liberal. Hall (2012) está en lo cierto cuando señala que el modo de producción de conocimientos y de investigación en las humanidades continúa relacionado con la idea indivisible, individual y liberal del autor humanista. Los académicos se encuentran inmersos en una forma de generación de ideas, teorías, publicación y diseminación del conocimiento que busca hacer una contribución autoritaria, contundente y magistral. Esto, a mi juicio, es de gran importancia para entender por qué quizás muchos académicos no han entrado en la discusión de la cultura libre. A diferencia de las industrias editoriales o de la cultura, cuya defensa de los derechos de propiedad intelectual tiene que ver con el reclamo de derechos económicos, en la producción intelectual o artística esto tiene que ver más bien con el derecho moral, con la búsqueda de la permanencia del nombre propio del autor. Finalmente, ¿qué es lo que nos queda de los grandes pensadores de las disciplinas humanísticas o de las ciencias sociales? Por cierto que sus contribuciones intelectuales, pero también, y no menos importante, sus nombres.

Los derechos de propiedad intelectual no fueron creados con el fin de limitar el acceso al conocimiento. Por el contrario, tenían como objetivo proteger al autor, no solo del plagio, sino también frente a la naciente industria editorial en el siglo XVI. No obstante, al entrar estos derechos en la 
lógica capitalista de producción, se han implementado políticas que buscan endurecerlos y limitar las posibilidades de que los mismos autores puedan decidir respecto a las formas de distribución de sus creaciones, ya que necesariamente debían insertarse en la lógica de las editoriales. Se supone que, bajo este marco regulatorio, los autores podían además recibir beneficios económicos de su obra, lo que finalmente ha terminado en manos de las editoriales también y, en el caso de las publicaciones académicas, nos parece que esto es más salvaje aún ${ }^{10}$. Incluso, aunque las publicaciones estén completamente disponibles en Internet de forma gratuita, como el caso de muchas revistas académicas latinoamericanas que se mencionan en el estudio de Cerda y Lara (2011), la omisión respecto a las licencias provoca que los artículos queden automáticamente sujetos a las leyes de copyright, lo cual significa que los artículos son accesibles pero no reproducibles ni utilizables fuera del contexto de la revista (aunque esto en la práctica se haga igual).

Frente a esta situación, consideramos que es importante reforzar el modelo de circulación del conocimiento que ya existe en América Latina y que se ha visto potenciado con el desarrollo de Internet. Redes de revistas académicas como RedALyC, Scielo, Latindex, y otras, fomentan la libre circulación del conocimiento al incluir revistas que permiten acceder libremente a sus artículos. Por otra parte, estas redes han sido fundamentales para difundir y fomentar la investigación en la región. Quizás la tarea pendiente es trabajar en los temas de licenciamiento que señala el estudio de Cerda y Lara (2011). Por otra parte, las instituciones universitarias y de investigación de nuestros países deberían evaluar positivamente la publicación de los académicos en revistas indexadas en sistemas latinoamericanos, como Scielo, y no que su valoración esté por debajo de índices como los

\footnotetext{
${ }^{10}$ Ya señalaba Bourdieu (1997) en su análisis de la violencia simbólica que en el área artística, perfectamente extrapolable a lo que sucede en la academia, existe una ideología que busca excluir el lenguaje mercantil, negar lo económico. Por eso el editor no se llama comerciante de libros: hacerlo sería hacer explícitas unas prácticas que funcionan en silencio y en la complicidad entre editores, autores y lectores. En esta cita, el autor grafica esta violencia: "El editor dice a un joven autor que tiene dificultades para llegar a fin de mes ‘ $¡$ Mire a Beckett, nunca ha cobrado ni un céntimo de sus derechos de autor' y el pobre escritor no sabe dónde meterse, pues no está seguro de ser Beckett, pero sí lo está de que, a diferencia de Beckett, tiene la bajeza de reclamar dinero" (Bourdieu, 1997, p. 184).
} 
que hemos mencionado (WoS y Scopus) ${ }^{11}$. Esto, aparte de fomentar la libre circulación de las investigaciones financiadas con fondos públicos, permite que apuntemos a un público más cercano, y no que nuestras investigaciones queden encerradas en un modelo de publicación pagado y donde los indicadores de lectura y de impacto señalan que prácticamente nadie lee esas investigaciones.

En este sentido, es importante desarrollar estrategias que permitan profundizar y ampliar un modelo no lucrativo de circulación de conocimientos, el cual se practica hace bastante tiempo en nuestra región y que preserva el espacio de lo común frente al movimiento privatizador que hemos descrito. Para lograr este objetivo es fundamental generar mayores incentivos desde las instituciones académicas para publicar en revistas que fomentan el libre acceso a sus contenidos, así como también repensar nuestros propios indicadores de evaluación de revistas, algo que Scielo ha realizado durante bastante tiempo, así como otras organizaciones lo están haciendo actualmente, como la red LATINOAMERICANA ${ }^{12}$.

\section{INTELECTUALES Y ACADÉMICOS PIRATAS}

El análisis que hemos presentado hasta ahora busca profundizar en un debate que se está realizando actualmente en diversos espacios académicos, seminarios y congresos latinoamericanos. En este artículo apostamos por realizar un llamado a desobedecer los parámetros impuestos actualmente por las publicaciones académicas que limitan la circulación del conocimiento, donde el reforzamiento de los derechos de propiedad intelectual tiene una motivación principalmente económica. Tal como hicieron Aaron

${ }^{11}$ A pesar de celebrar que Scielo sea un sistema que promueve el acceso abierto, es necesario revisar algunas de sus políticas de evaluación de revistas. Este es un tema en el que no profundizaremos en este artículo, pero es importante dejarlo planteado. Los criterios de evaluación de las revistas que se aplican a aquellas que pertenecen a las humanidades muchas veces no consideran su diferencia con las revistas provenientes de otras áreas, principalmente las ciencias, donde la forma en que se produce y presenta el conocimiento es diferente. Consideramos que la evaluación, tanto de revistas y artículos es fundamental y necesaria, pero deben revisarse los criterios de evaluación, dado que existen importantes divergencias en el tipo de investigación y resultados que las diferentes áreas producen.

${ }^{12}$ La red LATINOAMERICANA fue creada en el año 2014 y se constituyó como una asociación de revistas académicas de humanidades y ciencias sociales que tengan como foco Latinoamérica y el Caribe. Más información sobre sus objetivos y el trabajo realizado puede encontrarse en su web https://revistaslatinoamericanas.org/ 
Swartz y aquellos académicos que acudieron al llamado de \#pdftribute, o los científicos que decidieron no colaborar con Elsevier ${ }^{13}$. Es decir, una estrategia de boicot y sabotaje, de liberar nuestras publicaciones aún sujetas a ciertos aspectos nocivos del copyright, de negarse a publicar en revistas que no permitan compartir los artículos, que cobren por acceder a éstos, negarse finalmente a entrar en el circuito de privatización de conocimiento. O más bien, salirse de él.

¿Qué tenemos que decir desde las humanidades, y desde Latinoamérica, teniendo en consideración que son las áreas más afectadas por el modelo económico neoliberal $\mathrm{y}$, en consecuencia, producimos conocimientos en condiciones precarias? El modelo de acceso abierto, como creative commons, parece ser una buena alternativa, ya que permite publicar sin ceder los derechos intelectuales a las editoriales. Por otro lado, permite que más personas puedan acceder al conocimiento, ya que para que un artículo sea de acceso abierto se deben respetar ciertas garantías mínimas, como la reproducción y difusión. Sin embargo, también se podría decir que si bien esta forma de distribución del conocimiento representa una diferencia con el modelo tradicional, no tiene necesariamente nada inherentemente emancipatorio o radical. Es una nueva forma de regular la circulación de saberes en la era digital, pero no representa un cuestionamiento de las formas de producción del conocimiento asociadas a la autoría moderna. Sin embargo, debemos reconocer las semillas de transgresión que el modelo representa y enfocarnos en prácticas de apertura hacia otros modelos de distribución basados en el compartir y no en la limitación del acceso al conocimiento.

El acceso abierto escapa en muchos aspectos a las formas dominantes de propiedad intelectual. ¿Existe la voluntad de los académicos e intelectuales

${ }^{13}$ Existen varias acciones de "desobediencia" como el que ejemplificamos con el caso de Aaron Swartz. El artículo de Hall (2012) describe cómo Peter Suber, una de las voces líderes del movimiento por el acceso abierto, se negó a participar como evaluador en cualquier revista asociada a la Association of American Publishers (AAP), mientras ésta no reconsiderara su apoyo al Research Works Act, una ley propuesta en diciembre de 2011 que prohíbe el acceso libre a todas aquellas publicaciones o investigaciones financiadas con fondos estatales, lo cual restringe severamente el acceso a información científica. Winston Hide renunció a su labor como editor de la revista Genomics, aludiendo a que no era posible trabajar en un sistema que pone el beneficio económico por sobre el acceso al conocimiento. Él experimentó personalmente las dificultades para acceder a publicaciones científicas cuando estudiaba en Sudáfrica, por el elevado costo en el acceso y porque, y es la tónica en los países en desarrollo, las universidades no son capaces de pagar los altos costos de las suscripciones. Algo parecido hizo Timothy Gowers, matemático de la Universidad de Harvard, iniciando un boicot contra las revistas publicadas por Elsevier, compañía editorial que publica literatura médica y científica, por su apoyo al Research Works Act. Todas estas acciones se enmarcan en lo que se ha denominado la primavera académica. 
latinoamericanos de salir de ese modelo de publicación dominante, de la industria de producción de papers que privatiza el conocimiento? ¿Somos capaces de negarnos a publicar en editoriales o revistas que no permiten compartir nuestras producciones? ¿Qué pasaría si nos convirtiéramos en intelectuales-académicos piratas, parafraseando a Hall (2012)? Se trata de elecciones difíciles. Sin embargo podemos partir por intentar publicar en revistas de acceso abierto y exigir que en las publicaciones de nuestros artículos y libros se utilice algún tipo de licenciamiento creative commons.

Coincidiendo con lo que plantea Hall (2012), debemos reflexionar sobre si seguimos ejerciendo la labor de actuar para o hablar sobre los movimientos sociales, es decir, apoyar los movimientos desde fuera, o actuar en sus términos o con los movimientos sociales y asumir la responsabilidad de modificar la práctica privatizadora del conocimiento que impera en la universidad y las instituciones que fomentan la investigación. Quienes sientan atacada su "identidad" intelectual o profesional al incurrir en estas prácticas, es decir, el miedo a poner a libre disposición los conocimientos por temor al plagio o la copia, deben tener presente que la labor académica y el trabajo intelectual ya están siendo atacados con los recortes de presupuestos y la inestabilidad laboral presente en el área de las humanidades y ciencias sociales. Frente al contexto descrito, consideramos que no tenemos mucho que perder.

\section{REFERENCIAS}

Benjamin, W. (2007). The Work of Art in the Age of Mechanical Reproduction. En: Illuminations. Essays and Reflections. New York: Random House.

Bourdieu, P. (1997). Razones prácticas. Sobre la teoría de la acción. Barcelona: Editorial Anagrama.

Bunz, M. (2007). La utopía de la copia. El pop como irritación. Buenos Aires: Interzona Editora.

Cerda, A. y Lara, J. C. (2011). Políticas editoriales de publicaciones académicas en línea en Latinoamérica. Santiago: ONG Derechos Digitales, Disponible en: https://www.derechosdigitales.org/wp-content/uploads/Informe-Politicas_Editoriales_de_Publicaciones1.pdf (Acceso, 10 octubre 2015).

Cetto, A. M. y Alonso-Gamboa, J. (2014). "Latindex y el acceso abierto". Revista Digital Universitaria, 15(10). Disponible en: http://www.revista.unam.mx/ vol.15/num10/art76/\# (Acceso, 15 septiembre 2015).

Foucault, M. (2010). ¿Qué es un autor? Editado por Silvio Mattoni y Daniel Link. Buenos Aires: El Cuenco de Plata.

Hall, G. (2012). "Pirate Radical Philosophy". Radical Philosophy, journal of socialist and feminist philosophy, 173, 33-41, mayo/junio. Disponible en: 
http://www.radicalphilosophy.com/commentary/pirate-radical-philosophy-2. (Acceso, 10 febrero 2015).

Santos Herceg, J. (2012). "Tiranía del paper. Imposición institucional de un tipo discursivo". Revista Chilena de Literatura, 82, 197-217, noviembre. Disponible en: http://www.revistaliteratura.uchile.cl/index.php/RCL/article/ viewFile/24871/26233 (Acceso, marzo 2015). 